Supporting Information

Synthesis of Porous Si/C Composite Nanosheets from Vermiculite with Hierarchical Structure as High-Performance Anode for

\title{
Lithium-Ion Battery
}

Xi Huang, Dingcheng Cen, Run Wei, Hualin Fan and Zhihao Bao*

Shanghai Key Laboratory of Special Artificial Microstructure Materials and Technology, School of Physics Science and Engineering, Tongji University, Shanghai 200092, China. E-mail: zbao@tongji.edu.cn. 
Table S1. Metal element impurity concentration $\left(\mathrm{mg} \mathrm{kg}^{-1}\right)$ of the expanded vermiculite and porous silicon measured by ICP-OES. After the whole treatment, the metal impurity was greatly removed.

\begin{tabular}{cccccccc}
\hline & $\mathbf{M g}$ & $\mathbf{A l}$ & $\mathbf{F e}$ & $\mathbf{K}$ & $\mathbf{C a}$ & $\mathbf{P}$ & $\mathbf{T i}$ \\
\hline $\begin{array}{c}\text { Before } \\
\text { treatment }\end{array}$ & $7.11 \times 10^{4}$ & $6.70 \times 10^{4}$ & $1.23 \times 10^{5}$ & $4.43 \times 10^{4}$ & $8.67 \times 10^{3}$ & $6.12 \times 10$ & $1.10 \times 10^{4}$ \\
$\begin{array}{c}\text { After } \\
\text { treatment }\end{array}$ & $6.13 \times 10^{3}$ & $1.15 \times 10^{4}$ & $1.65 \times 10^{3}$ & $2.58 \times 10^{2}$ & $2.73 \times 10^{2}$ & $8.67 \times 10$ & $5.11 \times 10^{2}$ \\
\hline
\end{tabular}
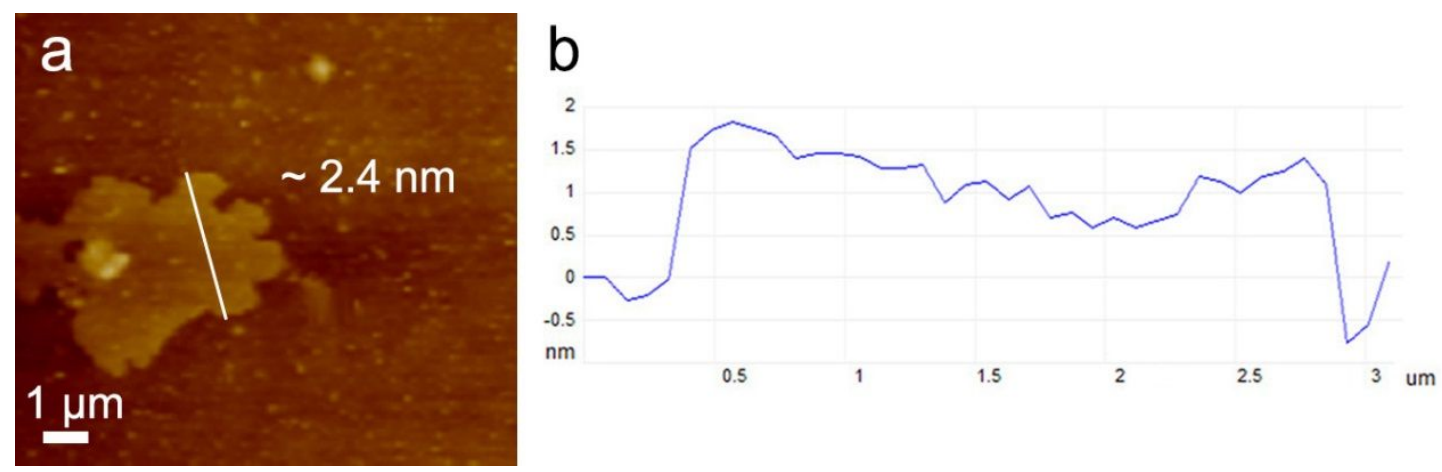

Figure S1. (a) AFM image of the carbon layer after $\mathrm{pSi} / \mathrm{C}$ sample etching in hydrofluoric acid. (b) Section line analysis as indicated.

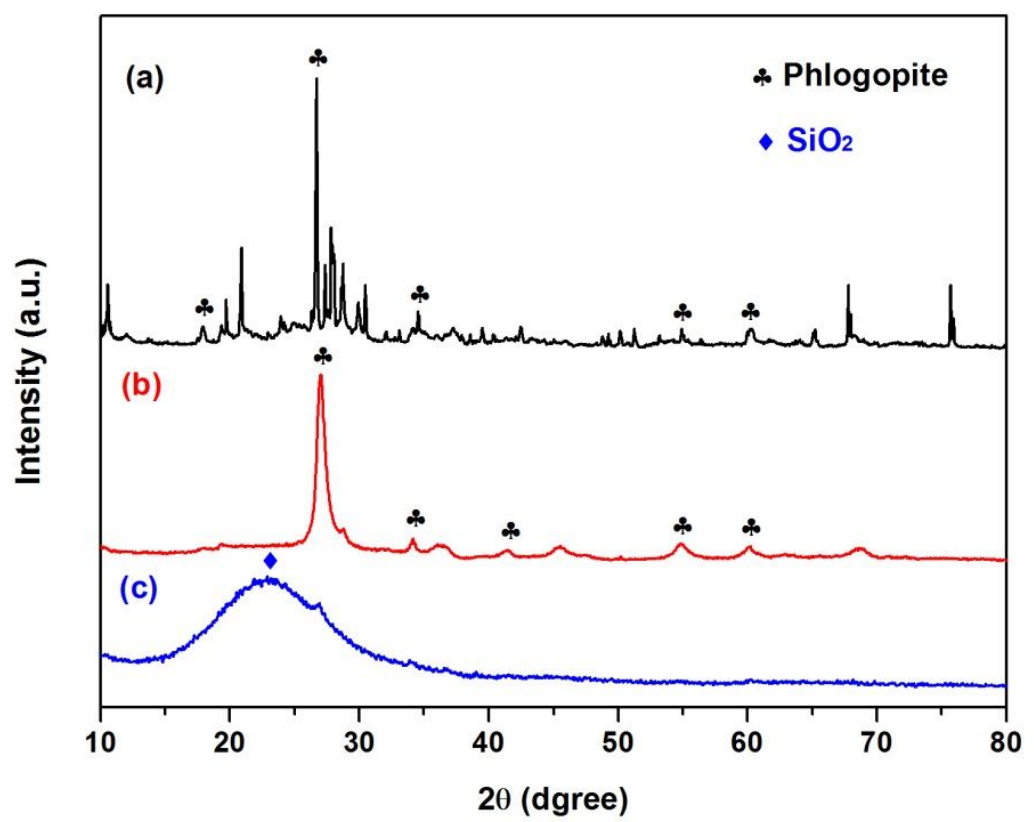

Figure S2. XRD patterns of (a) vermiculite, (b) carbon coated expanded vermiculite and (c) carbon coated expanded vermiculite after $\mathrm{HCl}$ etching. 

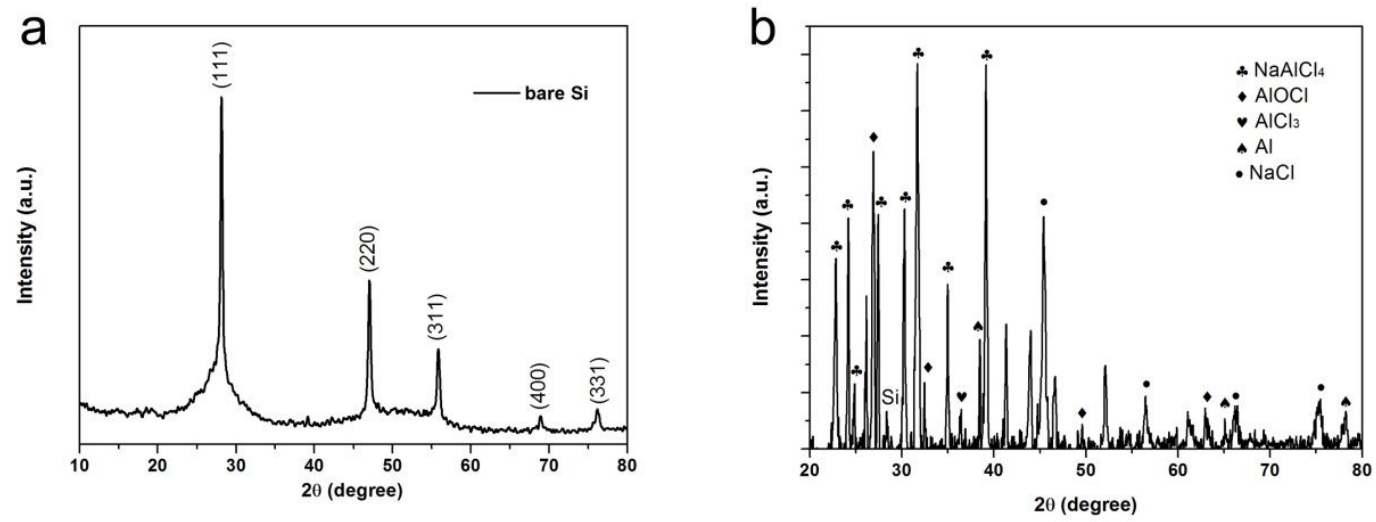

Figure S3. XRD patterns of (a) bare Si and (b) the crude product of the carbon coated expanded vermiculite after reduction.

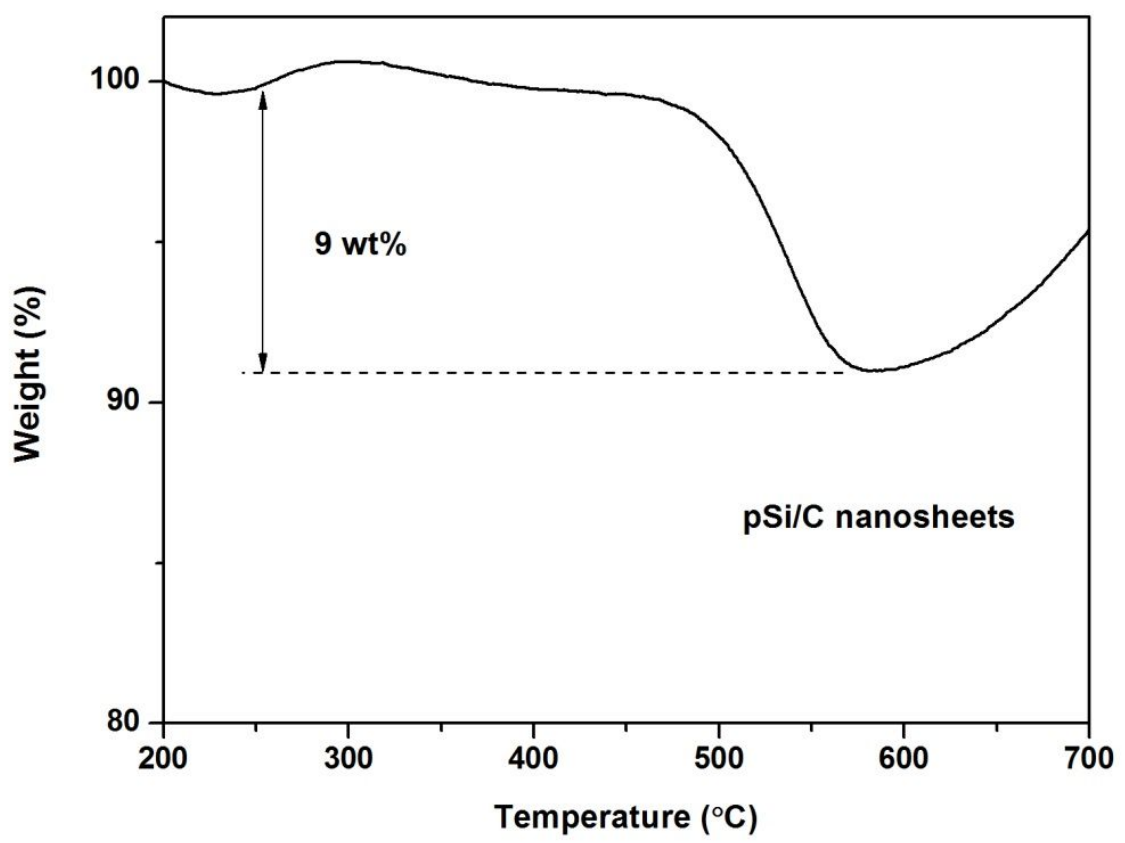

Figure $\mathbf{S 4}$. TGA curve of the $\mathrm{pSi} / \mathrm{C}$ composite nanosheets. 


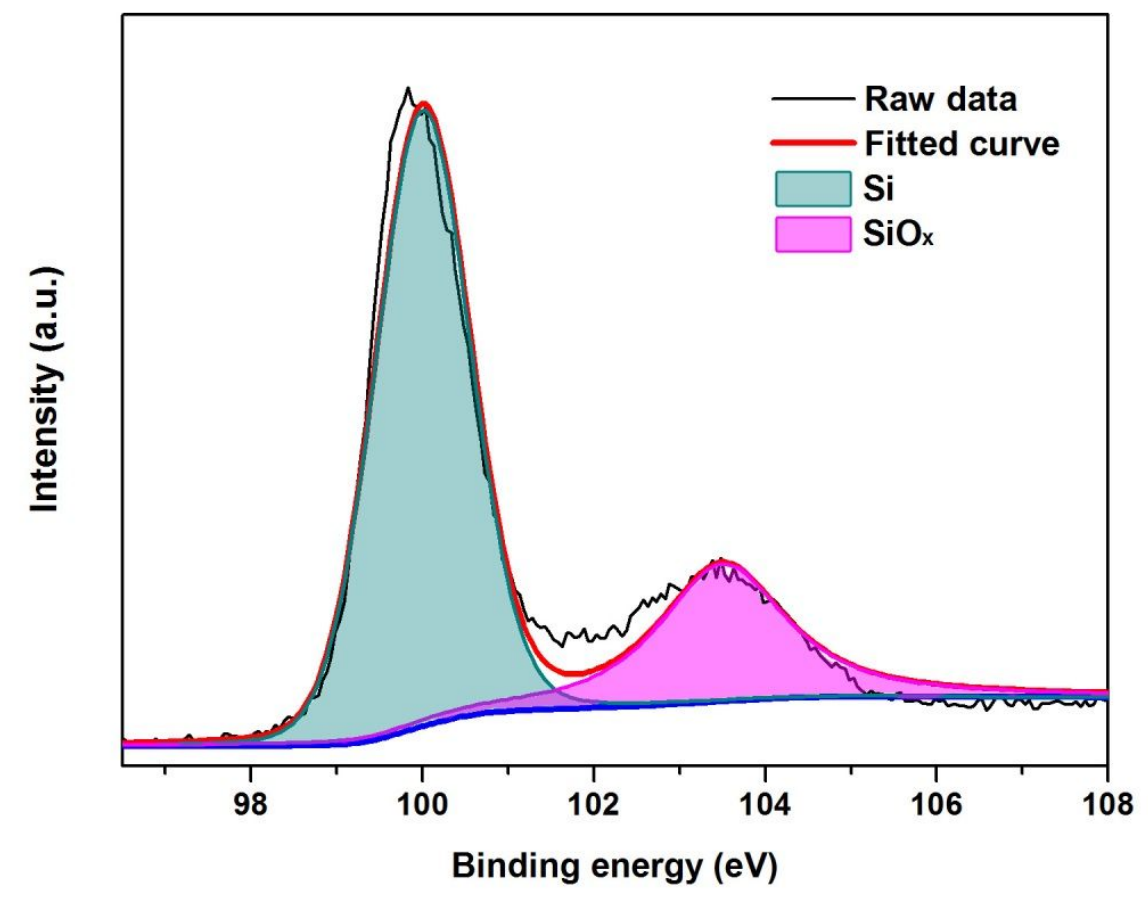

Figure S5. High-resolution Si $2 p$ XPS spectrum of $\mathrm{pSi} / \mathrm{C}$ composite nanosheets.
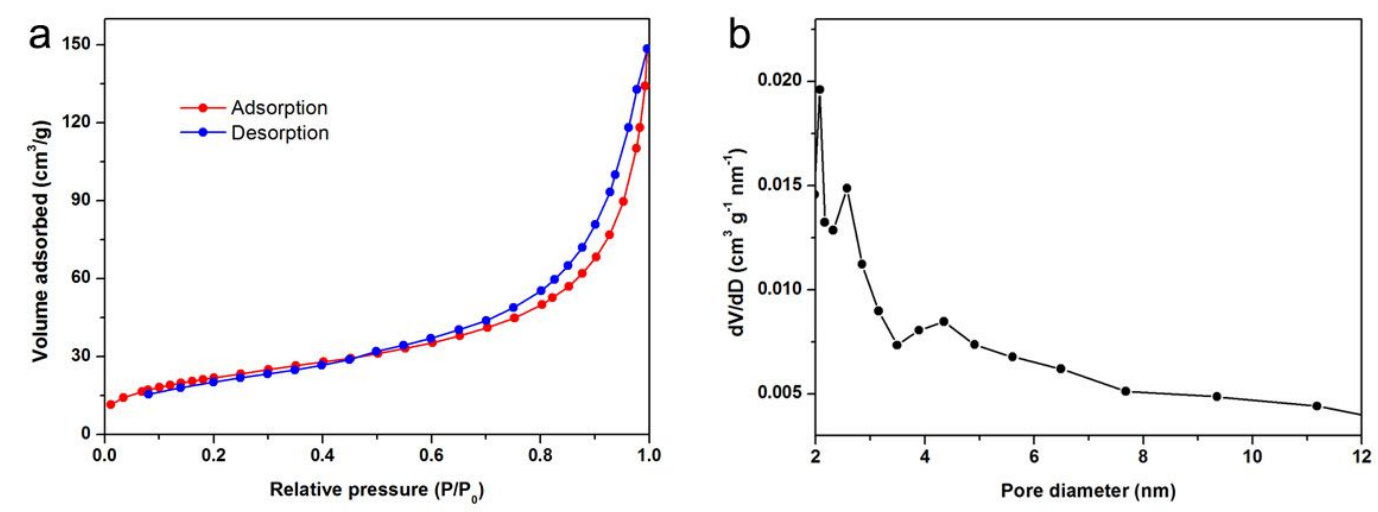

Figure S6. (a) Nitrogen adsorption-desorption curve. (b) Barrett-Joyner-Halenda pore size distribution of $\mathrm{pSi} / \mathrm{C}$ composite nanosheets. 

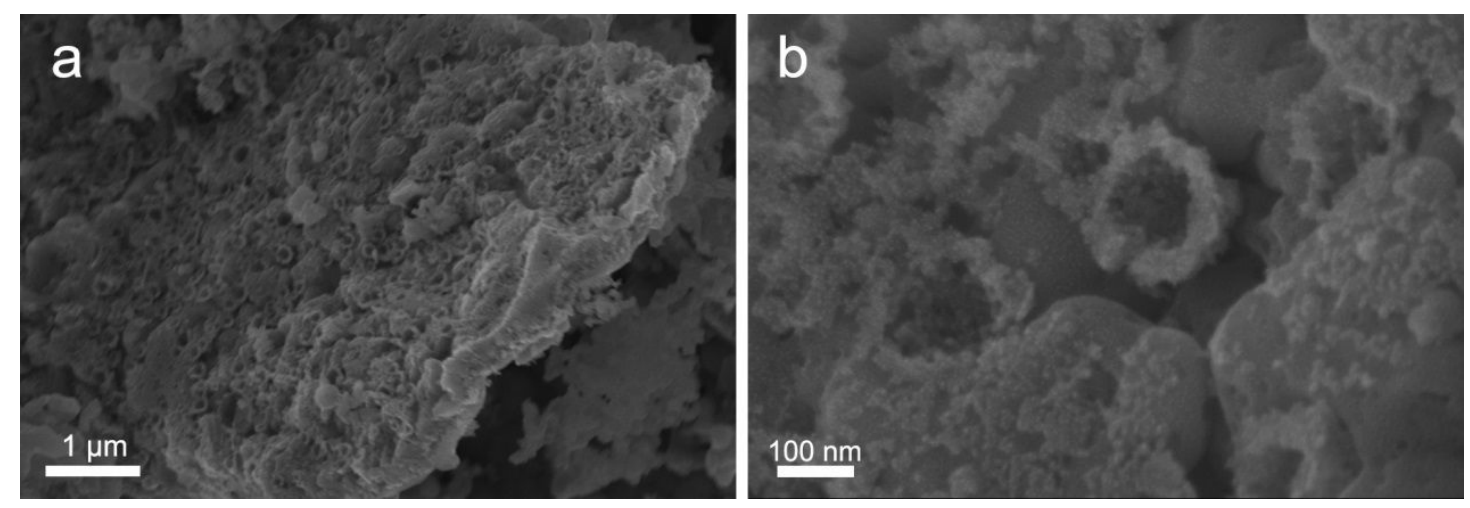

Figure S7. (a, b) SEM images of bare Si.
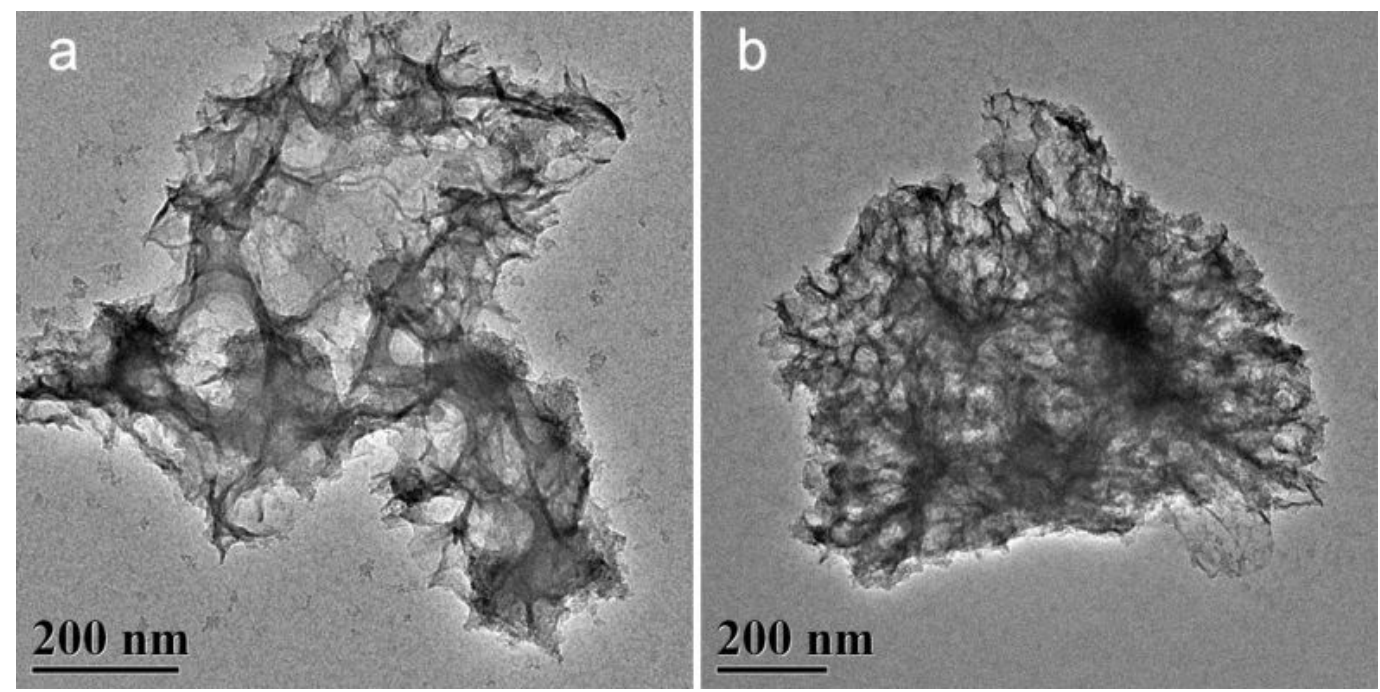

Figure S8. TEM images of (a) the bare $\mathrm{Si}$ and (b) pSi/C composite after cycling 100 times.
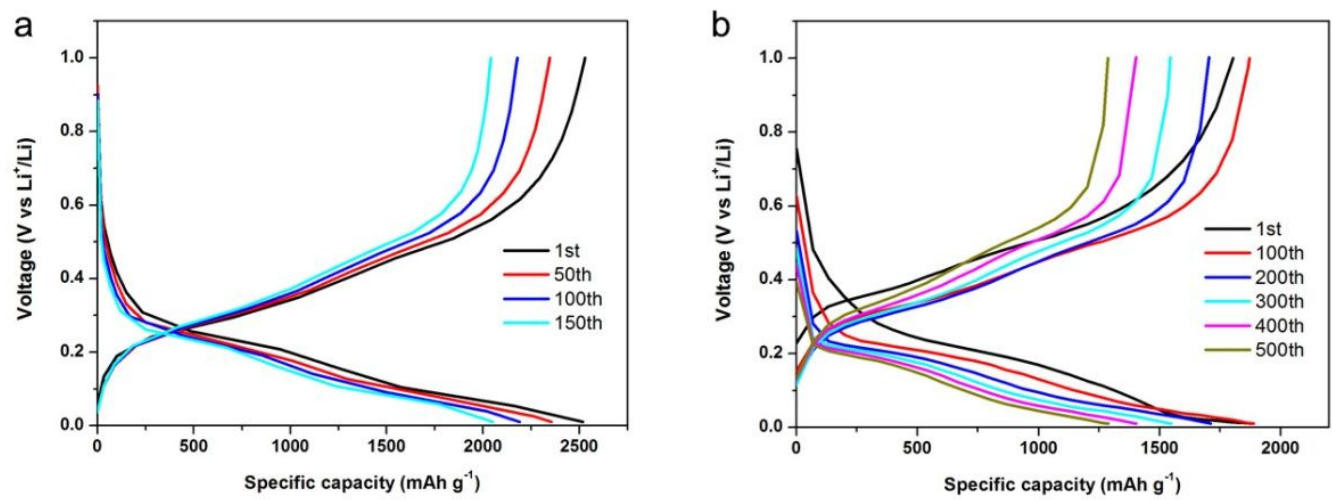

Figure S9. Galvanostatic discharge/charge voltage profiles of typical cycles of $\mathrm{pSi} / \mathrm{C}$ electrode at (a) $1 \mathrm{~A} \mathrm{~g}^{-1}$ and (b) $4 \mathrm{~A} \mathrm{~g}^{-1}$. 

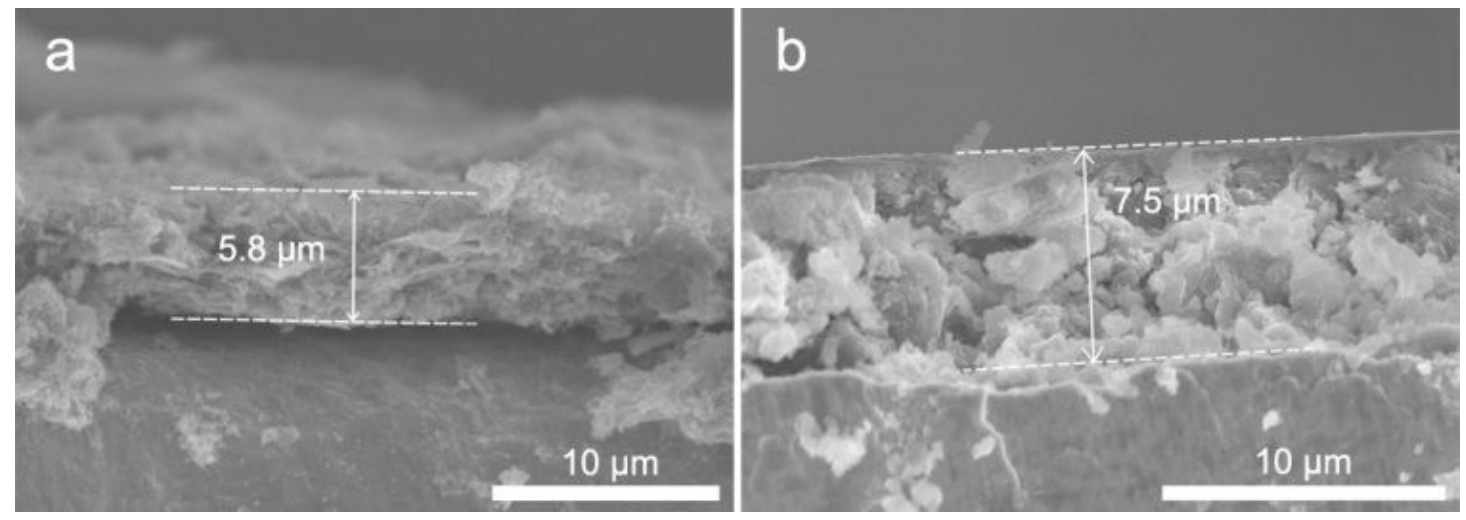

Figure S10. Cross-sectional SEM images showing the volume expansion of the $\mathrm{pSi} / \mathrm{C}$ electrodes (a) before electrochemical test, and (b) after 100 cycles at $1.0 \mathrm{~A} \mathrm{~g}^{-1}$.

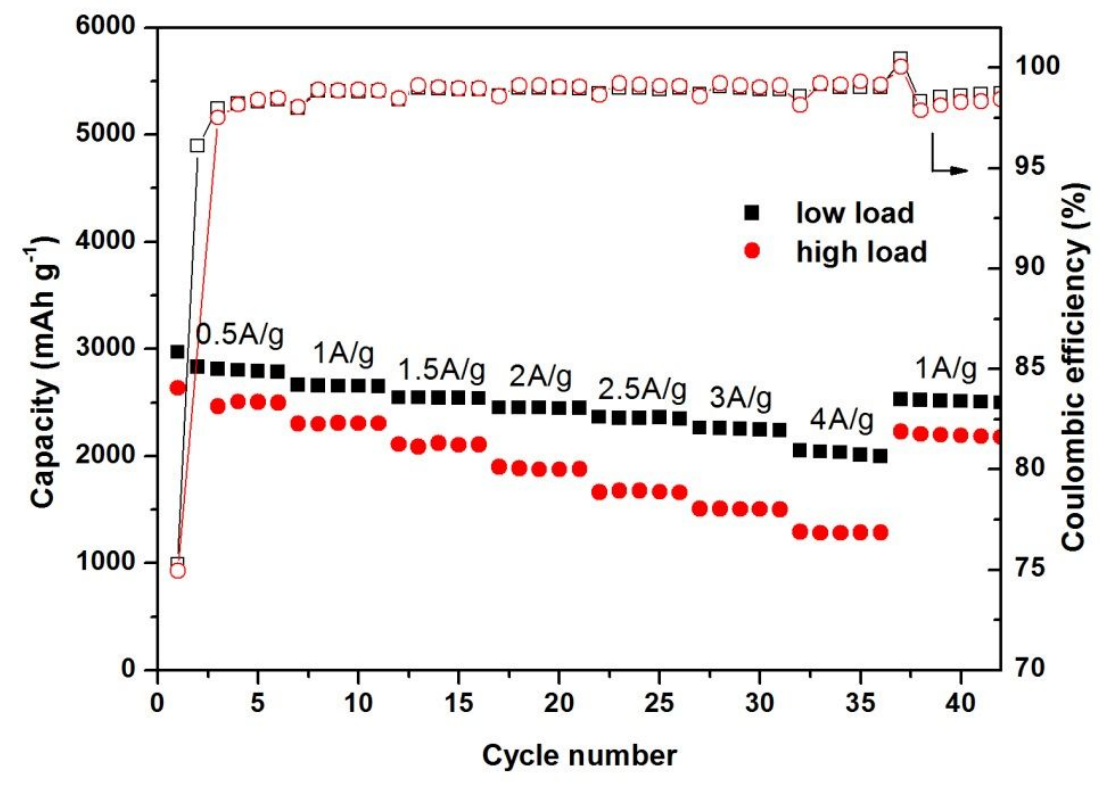

Figure S11. Rate capability of pSi/C electrode at different mass loading. 
Table S2. A summarization of electrochemical properties of various silicon-based materials.

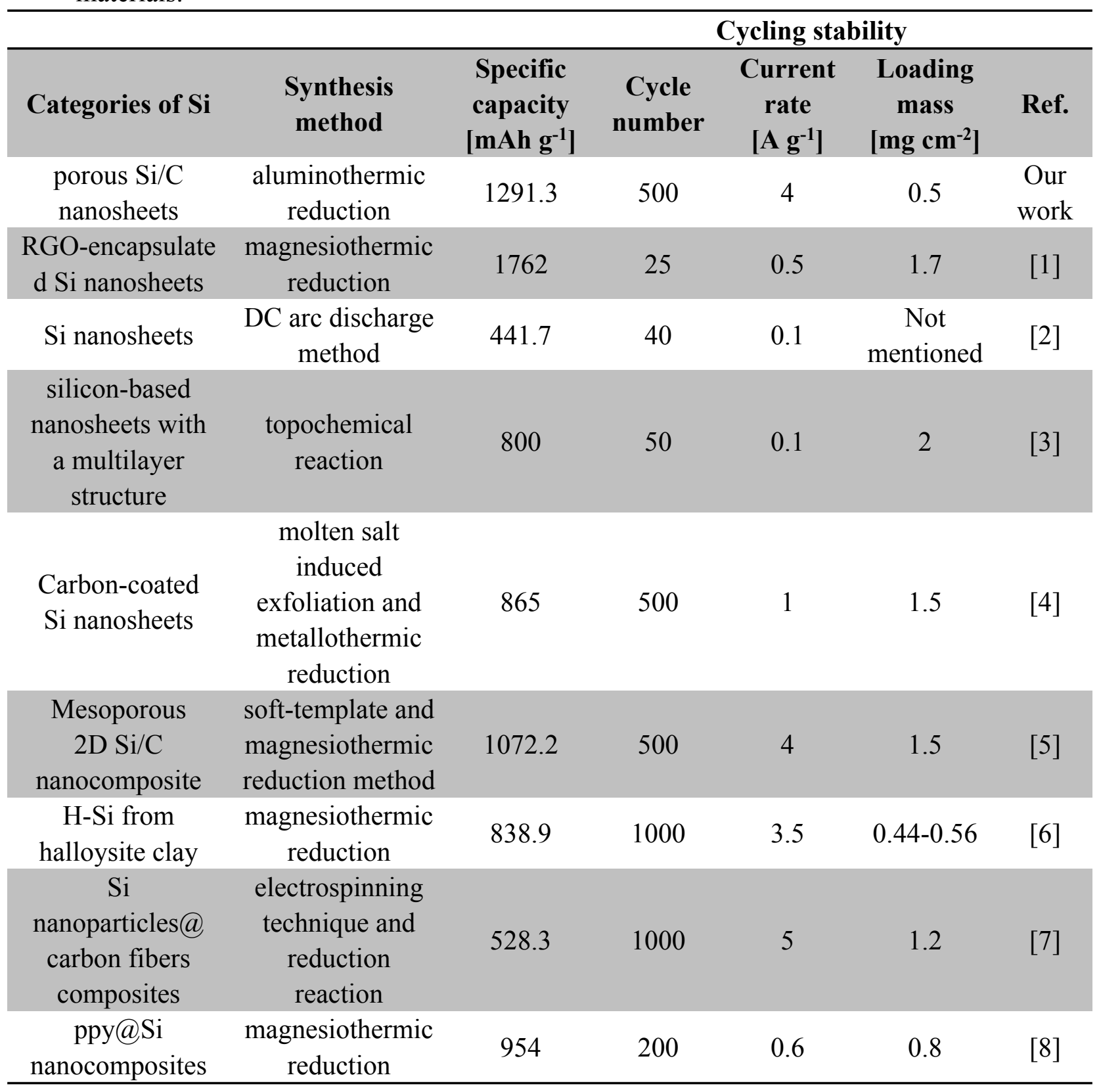

Table S3. The simulation values of parameters in equivalent circuit of Nyquist plots of the bare $\mathrm{Si}$ and $\mathrm{pSi} / \mathrm{C}$ anodes before and after cycling.

\begin{tabular}{|c|c|c|c|c|c|}
\hline & $\begin{array}{c}R \\
{[\Omega]}\end{array}$ & $\begin{array}{l}R_{\text {ct }} \\
{[\Omega]}\end{array}$ & $\begin{array}{l}\mathrm{CPE} \\
{[\mu \mathrm{F}]}\end{array}$ & $\begin{array}{c}\sigma \\
{\left[\Omega / \mathbf{s}^{-1 / 2}\right]}\end{array}$ & $\begin{array}{c}D \\
{\left[\mathrm{~cm}^{2} \mathrm{~s}^{-1}\right]}\end{array}$ \\
\hline Bare Si & 1.8513 & 985.6 & 1.87 & 1359.2 & $\begin{array}{c}1.41 \times 10 \\
16\end{array}$ \\
\hline $\begin{array}{c}\text { Bare Si after } \\
\text { cycling }\end{array}$ & 5.4755 & 386.7 & 0.428 & 396.2 & $\begin{array}{c}1.66 \times 10 \\
15\end{array}$ \\
\hline $\mathrm{pSi} / \mathrm{C}$ & 1.8228 & 314.5 & 0.84 & 489.7 & $\begin{array}{c}1.09 \times 10 \\
15\end{array}$ \\
\hline $\mathrm{pSi} / \mathrm{C}$ after & 3.8278 & 34.4 & 0.42 & 30.2 & $2.86 \times 10$ \\
\hline
\end{tabular}



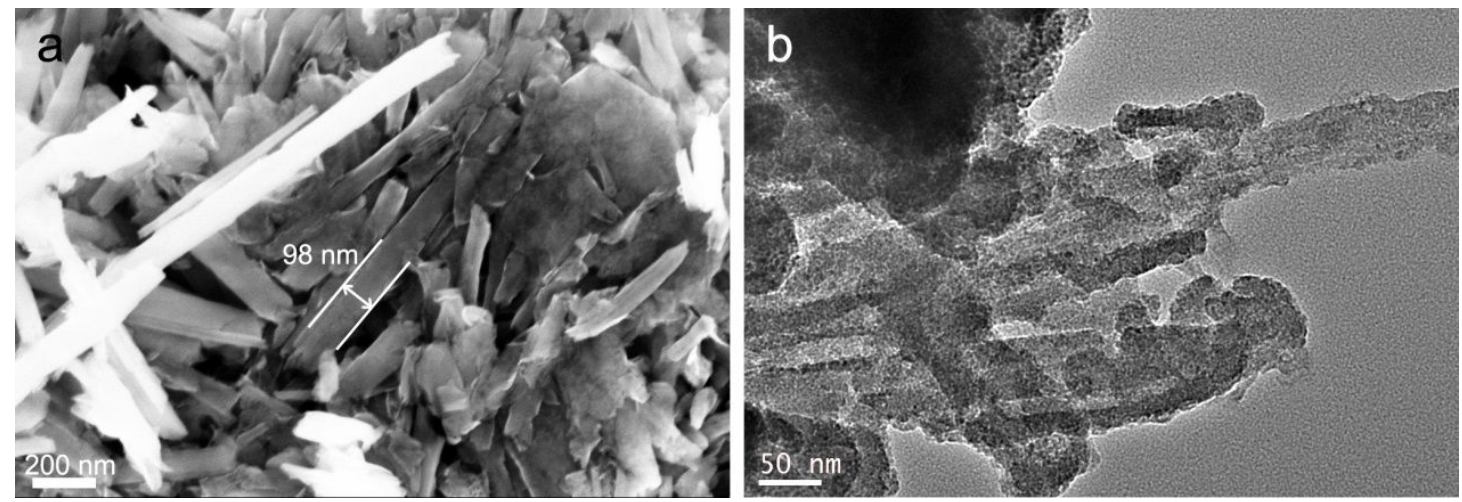

Figure S12. The morphology of carbon-coated Halloysite before and after reduction. (a) SEM image of Halloysite. (b) TEM of $\mathrm{pSi} / \mathrm{C}$ composite nanotubes.

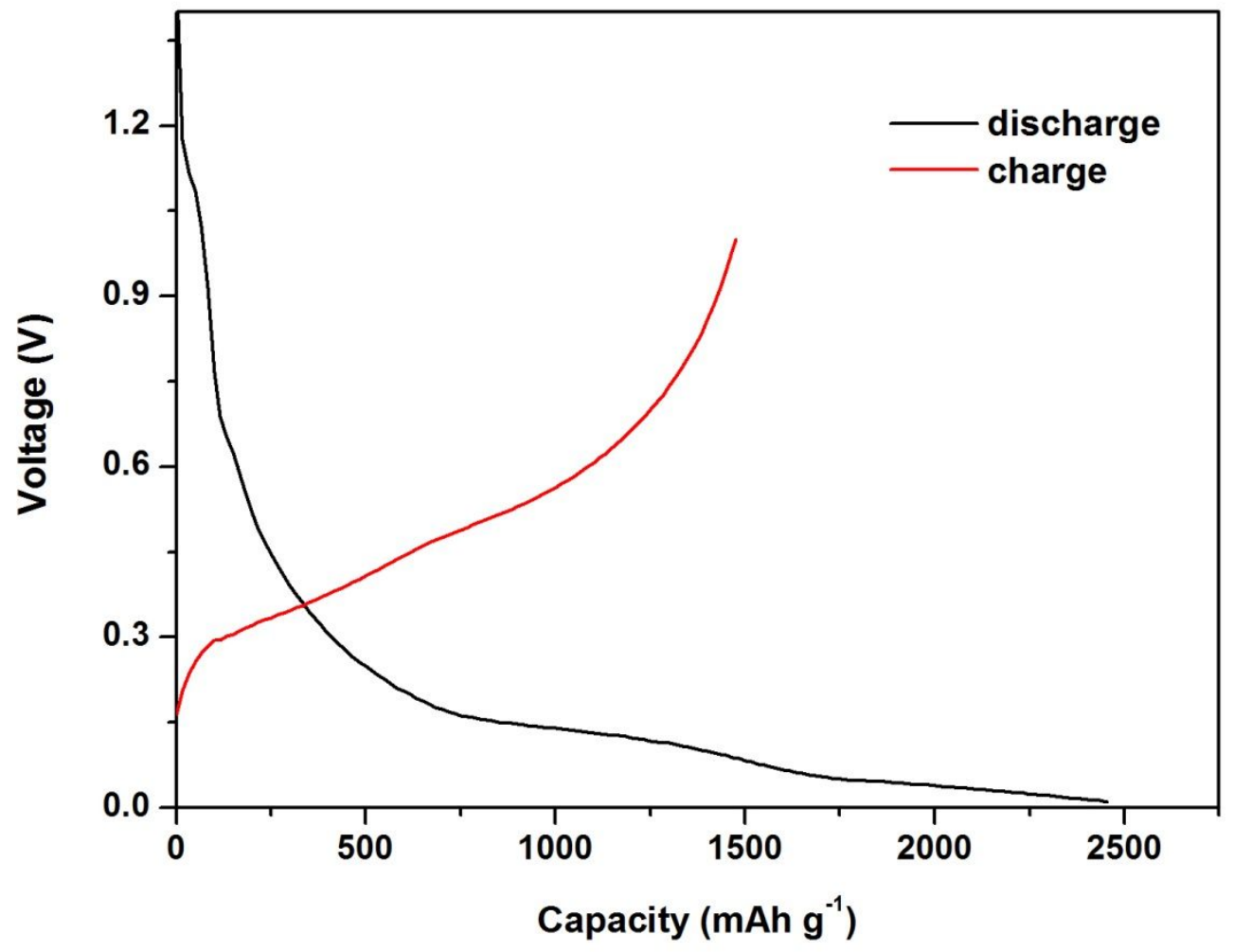

Figure S13. The galvanostatic initial cycle discharge/charge voltage profiles at a current density of $1 \mathrm{~A} \mathrm{~g}^{-1}$ of $\mathrm{pSi} / \mathrm{C}$ composite nanotube electrode. 


\section{References}

1. Kim, W. S.; Hwa, Y.; Shin, J. H.; Yang, M.; Sohn, H. J.; Hong, S. H. Scalable Synthesis of Silicon Nanosheets from Sand as an Anode for Li-Ion Batteries. Nanoscale 2014, 6, 4297-4302.

2. Yu, X.; Xue, F.; Huang, H.; Liu, C.; Yu, J.; Sun, Y.; Dong, X.; Cao, G.; Jung, Y. Synthesis and Electrochemical Properties of Silicon Nanosheets by DC Arc Discharge for Lithium-Ion Batteries. Nanoscale 2014, 6, 6860-6865.

3. Xu, K.; Ben, L.; Li, H.; Huang, X. Silicon-Based Nanosheets Synthesized by a Topochemical Reaction for Use as Anodes for Lithium Ion Batteries. Nano Res. 2015, 8, 2654-2662.

4. Ryu, J.; Hong, D.; Choi, S.; Park, S. Synthesis of Ultrathin Si Nanosheets from Natural Clays for Lithium-Ion Battery Anodes. ACS Nano 2016, 10, 2843-2851.

5. Chen, S.; Chen, Z.; Xu, X.; Cao, C.; Xia, M.; Luo, Y. Scalable 2D Mesoporous Silicon Nanosheets for High-Performance Lithium-Ion Battery Anode. Small 2018, 14, 1703361-1703371.

6. Zhou, X.; Wu, L.; Yang, J.; Tang, J.; Xi, L.; Wang, B. Synthesis of Nano-Sized Silicon from Natural Halloysite Clay and Its High Performance as Anode for Lithium-Ion Batteries. J. Power Sources 2016, 324, 33-40.

7. Liu, S.; Zhang, Q.; Yang, H.; Mu, D.; Pan, A.; Liang, S. Fabrication of Si Nanoparticles@Carbon Fibers Composites from Natural Nanoclay as an Advanced Lithium-Ion Battery Flexible Anode. Minerals 2018, 8, 180-189.

8. Sun, L.; Su, T.; Xu, L.; Du, H. B. Preparation of Uniform Si Nanoparticles for High-Performance Li-Ion Battery Anodes. Phys. Chem. Chem. Phys. 2016, 18, 1521-1525. 